Elsevier Editorial System(tm) for Journal of Cardiothoracic and Vascular Anesthesia

$$
\text { Manuscript Draft }
$$

Manuscript Number:

Title: Surgical repair of mitral valve disease in children: perioperative changes in respiratory function

Article Type: Original Research Article

Keywords: pulmonary hypertension, children, respiratory mechanics

Corresponding Author: Prof. Walid Habre, MD, PhD

Corresponding Author's Institution: Geneva Children's Hospital

First Author: Iliona Malaspinas, MD

Order of Authors: Iliona Malaspinas, MD; Ferenc Petak, PhD, DsC; Lionel Chok, MD; Anne Perrin, MD; Anne-Laure Martin, MD; Maurice Beghetti, MD, PhD; Walid Habre, MD, PhD 


\section{University of Geneva}

Department of Anaesthesiology, Pharmacology, and Intensive Care (APSI)

\section{Unit for Anesthesiological Investigations}

Walid Habre, MD, PhD

\section{Professor}

Ph: +4122 38275 04/ Fax: + 41223825485

E.Mail : Walid.Habre@ hcuge.ch

Geneva, 2016-01-06

Dear Editors,

Hereby we would like to submit our original research article entitled "Surgical repair of mitral valve disease in children: perioperative changes in respiratory function" for publication to Journal of Cardiothoracic and Vascular Anesthsia.

The authors agree with and are responsible for the data presented. The authors have no conflicts of interest related to the present study.

We all state that this work is original and has not been submitted for publication elsewhere or published in any significant part in any other journal. Furthermore, this paper will not be submitted elsewhere before a decision has been taken as to its acceptability by the journal.

We thank you for considering the manuscript for reviewing and we hope that you will find this work of high enough interest and quality.

Sincerely yours,

Iliona Malaspinas

Ferenc Petak

Lionel Chok

Anne Perrin

Anne-Laure Martin

Maurice Beghetti

Walid Habre (Corresponding author) 


\title{
SURGICAL REPAIR OF MITRAL VALVE DISEASE IN CHILDREN: PERIOPERATIVE CHANGES IN RESPIRATORY FUNCTION
}

\author{
Iliona Malaspinas ${ }^{\mathrm{a}, \mathrm{b}, \mathrm{c}}$, Ferenc Petak ${ }^{\mathrm{d}}$, Lionel Chok ${ }^{\mathrm{a}}$, Anne Perrin ${ }^{\mathrm{a}}$, Anne-Laure Martin ${ }^{\mathrm{c}}$, \\ Maurice Beghetti ${ }^{c}$, Walid Habre ${ }^{\mathrm{a}, \mathrm{b}}$
}

\footnotetext{
${ }^{a}$ Pediatric Anesthesia Unit, Geneva Children's Hospital, University Hospitals of Geneva, 6 Rue Willy-Donzé, CH-1205 Geneva, Switzerland

${ }^{\mathrm{b}}$ Unit for Anesthesiological Investigations, Department of Anesthesiology, Pharmacology and Intensive Care, University of Geneva, 1, rue Michel-Servet, CH-1211 Geneva, Switzerland ${ }^{\mathrm{c}}$ Pediatric Cardiology Unit, Geneva Children's Hospital, University Hospitals of Geneva, 6 Rue Willy-Donzé, CH-1205 Geneva, Switzerland

${ }^{\mathrm{d}}$ Department of Medical Physics and Informatics, University of Szeged, 9 Korányi fasor H6720 Szeged, Hungary
}

Corresponding author:

Prof W. HABRE

Pediatric Anesthesia Unit

Geneva Children's Hospital

University Hospital of Geneva

6, rue Willy Donzé, 1205 Geneva

Switzerland

$\mathrm{Ph}:+41223827504$

Fax: + 41223825485

e-mail: walid.habre@hcuge.ch

Acknowledgments: Financial Support and Grant: This study was funded by the Department of Anesthesiology, Pharmacology and Intensive Care of the University Hospitals of Geneva and by a grant from the Swiss National Science Foundation 3200B0-118231. 


\section{ABSTRACT}

Objective: To assess the profile of changes in airway (Raw) and respiratory tissue mechanics within a follow-up study performed in children with mitral valve disease, before and after surgical valve repair.

Design and Setting: Perioperative measurements in a prospective consecutive cross sectional study.

Participants: 24 children with congenital or post rheumatic mitral valve insufficiency.

Interventions: Input impedance of the respiratory system during spontaneous breathing was measured before, at 5 days and 3 weeks after mitral valve surgery. In addition, airway and respiratory tissue mechanics and pulmonary arterial pressure (Ppa) were also assessed under general anesthesia pre- and immediately postoperatively. Raw and respiratory tissue elastance were estimated from forced oscillatory impedance data by fitting an appropriate model.

Measurement and main results: Relating airway and respiratory tissue mechanics to agematched healthy controls revealed abnormal respiratory function $(135 \pm 6.2 \%$ and $148 \pm 13 \%$ in respiratory elastance and resistance, respectively, $\mathrm{p}<0.001)$. Improvement in the airway properties was observed immediately after surgery $(-15.2 \pm 3.4 \%, \mathrm{p}<0.005)$ and lasted for the study-period $(-19 \pm 4.1 \%, \mathrm{p}<0.001)$. Respiratory tissue elastance, which was correlated preoperatively to the diastolic Ppa, decreased only 5 days postoperatively $(-20.6 \pm 4.1 \%$, $\mathrm{p}<0.005)$. However, there was no evidence for a clear immediate effect of surgery on the tissue mechanical parameters measured intraoperatively despite a decrease in diastolic pulmonary pressure.

Conclusions: The role of the close cardiopulmonary interactions was evidenced from the present findings in the presence of mitral valve disease. Different underlying mechanisms responsible for the alterations in the compromised airway and respiratory tissue function can be inferred from these results.

Key words: pulmonary hypertension, children, respiratory mechanics 


\title{
SURGICAL REPAIR OF MITRAL VALVE DISEASE IN CHILDREN: PERIOPERATIVE CHANGES IN RESPIRATORY FUNCTION
}

\begin{abstract}
Objective: To assess the profile of changes in airway (Raw) and respiratory tissue mechanics within a follow-up study performed in children with mitral valve disease, before and after surgical valve repair.
\end{abstract}

Design and Setting: Perioperative measurements in a prospective consecutive cross sectional study.

Participants: 24 children with congenital or post rheumatic mitral valve insufficiency.

Interventions: Input impedance of the respiratory system during spontaneous breathing was measured before, at 5 days and 3 weeks after mitral valve surgery. In addition, airway and respiratory tissue mechanics and pulmonary arterial pressure (Ppa) were also assessed under general anesthesia pre- and immediately postoperatively. Raw and respiratory tissue elastance were estimated from forced oscillatory impedance data by fitting an appropriate model.

Measurement and main results: Relating airway and respiratory tissue mechanics to agematched healthy controls revealed abnormal respiratory function $(135 \pm 6.2 \%$ and $148 \pm 13 \%$ in respiratory elastance and resistance, respectively, $\mathrm{p}<0.001)$. Improvement in the airway properties was observed immediately after surgery $(-15.2 \pm 3.4 \%, \mathrm{p}<0.005)$ and lasted for the study-period $(-19 \pm 4.1 \%, \mathrm{p}<0.001)$. Respiratory tissue elastance, which was correlated preoperatively to the diastolic Ppa, decreased only 5 days postoperatively $(-20.6 \pm 4.1 \%$, $\mathrm{p}<0.005)$. However, there was no evidence for a clear immediate effect of surgery on the tissue mechanical parameters measured intraoperatively despite a decrease in diastolic pulmonary pressure.

Conclusions: The role of the close cardiopulmonary interactions was evidenced from the present findings in the presence of mitral valve disease. Different underlying mechanisms responsible for the alterations in the compromised airway and respiratory tissue function can be inferred from these results.

Key words: pulmonary hypertension, children, respiratory mechanics 


\section{INTRODUCTION}

Among the valvular heart diseases, mitral valve insufficiency is the most frequent malfunction encountered in clinical practice. While this disease is often the consequence of cardiac ischemia in adults, acute rheumatic fever due to group A streptococcal tonsillopharyngitis and the subsequent infectious pancarditis is the main cause of mitral valve disease in children ${ }^{1}$. This anomaly has a large public health impact in emerging countries with lack of available antibiotics ${ }^{2}$.

The cardiopulmonary interaction is exerted via complex interdependences either on the alveolo-capillary compartment or at the level of the bronchial tree closely surrounded by the pulmonary vessels. An expression of this interaction can be appreciated by the adverse respiratory symptoms in patients suffering from low left ventricular ejection fraction and congestive heart failure ${ }^{3,4}$. The resulting pulmonary vascular congestion compromises the airway and lung tissue mechanics ${ }^{5,6}$, which is manifested in the development of clinical symptoms, such as dyspnea, orthopnea, and wheezing ${ }^{7}$.

Numerous mechanisms may contribute to the respiratory clinical manifestations of mitral valve disease. The increase in postcapillary pulmonary pressure may lead to the development of interstitial edema with consequent uncoupling of the airways from the lung parenchyma and adverse alterations in the lung visco-elasticity ${ }^{8}$. Concomitantly, vascular engorgement in the pulmonary vascular bed may compress the bronchial wall and decrease the airway lumen $5,6,9$. As a long term consequence of lung congestion, chronic mitral valve disease may lead to cellular remodeling of the alveolar and bronchial walls, further compromising the lung function ${ }^{4,6,10-13}$. While several studies have demonstrated the potential beneficial effect of decrease in postcapillary pulmonary pressure on the improvement in lung function ${ }^{14,15}$, it is 
still unknown whether the decrease in capillary overload and/or the relief of the airway compression are responsible for this acute beneficial effect following surgical repair of mitral valve. Defining the primary mechanism may help the clinician understanding the clinical symptoms exerted by the patient and targeting the treatment accordingly.

Thus, we aim at characterizing the perioperative profile of the airway and respiratory tissue mechanics in children undergoing surgical repair of their mitral valve. We postulate that assessing the airway and tissue mechanical parameters separately will reveal different processes responsible for their contribution to the lung function alteration. We therefore hypothesize that airway and respiratory tissue mechanics exert different profile after reestablishing the mitral valve function, which decreases interstitial vascular engorgement.

\section{METHODS}

\section{Study population}

The measurement protocol was approved by the Pediatric Ethics Committee (No. 09-042 matped) of the University Hospitals of Geneva. All children included in the present study were of African origin and supported by a humanitarian mission (Terre des Hommes). They were from French-speaking African countries and were able to understand the information provided by the investigators, and participated freely in the study. The parent were aware and gave authorization of the possible involvement of their children into clinical studies, and the ethics committee agreed that the consent is given by the children's tutor or the medical director of the humanitarian charity on behalf of the parents. Thus, a written informed consent was obtained from the medical referee. Children were included in the study in a consecutive case series design, and those who refused participation were excluded without further consequences. Inclusion criteria consisted of the diagnosis and subsequent elective surgical 
repair of mitral valve disease. Children with chronic pulmonary diseases, obtained by clinical history, were excluded from the protocol.

\section{Forced oscillatory measurements in spontaneously breathing children}

The forced oscillatory technique (FOT) measurements were performed in accordance with the European Respiratory Society (ERS) guidelines ${ }^{16}$. A custom made device was applied to measure the input impedance of the respiratory system $\left(\mathrm{Zrs}_{\mathrm{sp}}\right)$ while the child performed normal breathing. Briefly, a loudspeaker generated a pseudorandom broad-band forcing signal between 4 and $26 \mathrm{~Hz}$, which was led through a plexiglass wave tube (ID $14 \mathrm{~mm}$, OD $20 \mathrm{~mm}$, $\mathrm{L}=17 \mathrm{~cm}$ ) attached to a disposable bacterial filter and mouthpiece. The bias tube of the system was flushed with $100 \%$ oxygen during the measurements to reduce rebreathing. Lateral pressures were measured at the loudspeaker end $\left(\mathrm{P}_{1}\right)$ and the distal end $\left(\mathrm{P}_{2}\right)$ of the wave-tube with miniature pressure transducers (ICS model 33NA002D, ICSensors, Milpitas, CA). These signals were low-pass filtered $(25 \mathrm{~Hz})$ and digitized $(128 \mathrm{~Hz})$. The pressure transfer function (P1/P2) was calculated by fast Fourier transformation from the 12-s recordings and the $\mathrm{Zrs}_{\mathrm{sp}}$ was computed as the load impedance of the wave-tube ${ }^{17}$.

During the data recording periods, the children were asked to wear a nose clip and to sit in an upright position. They were asked to breathing quietly through the mouthpiece while supporting their cheeks with their palms during these maneuvers in order to minimize upper airway shunting. Four to six technically acceptable measurements were made at each occasion and were ensemble-averaged for further analyses.

The resistive and elastic properties of the respiratory system were evaluated by fitting a simple resistance-compliance model of the respiratory system to the $\mathrm{Zrs}_{\mathrm{sp}}$ spectra ${ }^{18}$. The resistive parameter of this model reflects the flow resistance of the airways $\left(\operatorname{Raw}_{\mathrm{sp}}\right)$, while the compliance $\left(\mathrm{Crs}=1 / \mathrm{Ers}_{\mathrm{sp}}\right.$, where $\mathrm{Ers}_{\mathrm{sp}}$ is the respiratory elastance $)$ is related to the respiratory tissue stiffness. The parameters $\operatorname{Raw}_{\mathrm{sp}}$ and $\mathrm{Ers}_{\mathrm{sp}}$ were related to reference values obtained in 
healthy children by using similar methodology ${ }^{18}$. Since the children involved in the present study were severely underweight, reference equations based on the age were applied.

\section{Anesthesia and mechanical ventilation}

One day after completing the first set of $\mathrm{Zrs}_{\mathrm{sp}}$ measurements, children received oral midazolam for $(0.5 \mathrm{mg} / \mathrm{kg}) 30 \mathrm{~min}$ before anesthesia induction. Induction of anesthesia was achieved by either inhalation of sevoflurane (up to $6 \%$ ) or intravenously with etomidate (2-3 $\mathrm{mg} / \mathrm{kg}$ ). Endotracheal intubation with a cuffed tube was performed following the iv administration of atracurium $(0.5 \mathrm{mg} / \mathrm{kg})$. Analgesia was provided by iv administration of a bolus of of sufentanil $(0.5 \mu \mathrm{g} / \mathrm{kg})$ and ketamine $(0.15 \mathrm{mg} / \mathrm{kg})$, followed by the continuous infusion of sufentanil $(0.5$ to $1 \mu \mathrm{g} / \mathrm{kg} / \mathrm{h})$ and ketamine $(0.1 \mu \mathrm{g} / \mathrm{kg} / \mathrm{h})$. In addition, anesthesia was maintained with iv midazolam $(0.2 \mathrm{mg} / \mathrm{kg} / \mathrm{h})$. Additional iv boluses of atracurium $(0.3$ $\mathrm{mg} / \mathrm{kg}$ ) were administered to ensure neuromuscular blockade.

Children were mechanically ventilated in pressure-regulated mode (VT $8 \mathrm{ml} / \mathrm{kg}$ ), while maintaining a positive end-expiratory pressure (PEEP) of $5 \mathrm{cmH}_{2} \mathrm{O}$, an inspired oxygen fraction $\left(\mathrm{FiO}_{2}\right)$ of 0.5 , and setting the respiratory rate to achieve an end-tidal partial pressure of $\mathrm{CO}_{2}$ in the expired gas around $5.5 \mathrm{kPa}$.

\section{Low-frequency Forced oscillatory measurements in anesthetized children}

The measurement apparatus used for the respiratory impedance $\left(\mathrm{Zrs}_{\mathrm{OR}}\right)$ measurements in the anesthetized, mechanically ventilated children was detailed previously ${ }^{19}$. Before starting the oscillatory measurements, the lungs were inflated to a pressure of about $30 \mathrm{cmH}_{2} \mathrm{O}$ to standardize the volume history. The ventilation was suspended at end-expiration and the ETtube was switched into communication with the forced oscillatory equipment. In the resulting 8-sec apneic period, small-amplitude $\left(<2 \mathrm{cmH}_{2} \mathrm{O}\right.$ peak-to-peak $)$ pseudorandom pressure excitations incorporating multiple frequency components $(0.4-12 \mathrm{~Hz})$ were delivered by a 
loudspeaker into the trachea. The pressure in the loudspeaker chamber was set to $5 \mathrm{cmH}_{2} \mathrm{O}$ prior to the measurements to maintain the PEEP level during recordings.

A 12-mm-ID screen pneumotachograph connected to a differential pressure transducer (ICS model 33NA002D, ICSensors, Milpitas, CA) was used to measure the tracheal flow (V'). The tracheal pressure (Ptr) was measured with an identical pressure transducer through a polyethylene catheter (1.5-mm-OD). To exclude the ET tube impedance from the measurements, the tip of the intratracheal catheter (having several lateral holes) was positioned $1.5-2 \mathrm{~cm}$ beyond the distal end of the ET tube.

Four-to-six 8-s data epochs were collected at a mean transrespiratory pressure of $5 \mathrm{cmH}_{2} \mathrm{O}$ both immediately before sternotomy and after chest closure. In the latter case, the chest drain tubes were clamped to ensure a closed chest cavity. At least 1-min periods of mechanical ventilation were interposed between successive measurements. The signals of the transducers were low-pass filtered $(25 \mathrm{~Hz})$, and digitized $(256 \mathrm{~Hz})$. ZrsoR spectra were calculated from the Ptr and V' signals $\left(\mathrm{Zrs}_{\mathrm{OR}}=\mathrm{Ptr} / \mathrm{V}^{\prime}\right)$. The impedance curves collected before or after the surgery were ensemble-averaged in each child. The potential biasing effects of leak on the oscillatory measurements were excluded by checking the equality of the inspiratory and expiratory tidal volumes during mechanical ventilation and by monitoring the lack of a gradual fall in Ptr during the data collection.

To separate the airway and tissue mechanics, a model containing a frequency-independent airway resistance $\left(\mathrm{Raw}_{\mathrm{OR}}\right)$ and inertance $\left(\mathrm{Iaw}_{\mathrm{OR}}\right)$ in series with a constant-phase tissue model 20 including damping $\left(\mathrm{G}_{\mathrm{OR}}\right)$ and elastance $\left(\mathrm{H}_{\mathrm{OR}}\right)$ was fitted to the $\mathrm{Zrs}$ spectra by minimizing the differences between the measured and modeled impedance values. Impedance data at frequencies coinciding with the heart rate and its harmonics were omitted from the model fitting. 


\section{Hemodynamic measurements}

To assess the systolic $\left(\mathrm{Ppa}_{\mathrm{sys}}\right)$, diastolic $\left(\mathrm{Ppa}_{\mathrm{dia}}\right)$ and mean $\left(\mathrm{Ppa}_{\mathrm{mean}}\right)$ pulmonary artery pressure values, the pulmonary artery is directly punctured by the surgeon via a $24 \mathrm{G}$ needle immediately before cannulation of the aorta and after decannulation when the patient is weaned from cardiopulmonary bypass (CPB).

\section{Study protocol}

The study period covered 22 days with $\mathrm{Zrs}_{\text {sp }}$ measurements performed under spontaneous breathing the day before the surgery, and at 5 days postoperatively before clearance from the ward (Fig. 1). The last spontaneous FOT assessment was performed at day 21 in the outpatient setting during postoperative cardiology assessment and prior to return to their countries. The first set of $\mathrm{Zrs}_{\mathrm{OR}}$ measurements took place in the operating room under steady state conditions and before chest opening. The initial assessment of pulmonary hemodynamics was performed prior to aortic cannulation. Following mitral valve surgery, a second hemodynamic reading was made prior to sternal closure. The second set of Zrsor was collected after chest closure and before transferring the child to intensive care. All respiratory mechanics were performed 1 minute following a sigh (obtained by applying a pressure of 30 $\mathrm{cmH}_{2} \mathrm{O}$ for 10 seconds) to ensure a standardized volume history.

\section{Statistical analyses}

The scatters in the parameters were expressed by the SEM values. The Lilliefors test was used to test data for normality. All examined parameters or their log transformations were normally distributed (all $p>0.11$ ). The effects of time on the data obtained during spontaneous breathing were evaluated by one-way repeated measured ANOVA with time as repeated measures (within-subject) factor. Pairwise comparisons were performed on estimated marginal means 
by taking into account the presence or absence of interaction, p-values for multiple comparisons were corrected by the Holm-Sidak method. Respiratory mechanical or pulmonary hemodynamic data obtained in the anesthetized children were analyzed by using paired t-tests, as these data were all normally distributed $(\mathrm{p}>0.19)$. The Spearman correlation test was applied to test the strength of associations between the variables. Statistical tests were carried out with the significance level set at $\mathrm{p}<0.05$ by using SigmaPlot (version 12, Systat Software, Chicago, IL, USA).

\section{RESULTS}

Twenty-four children we enrolled into the study with (17 female and 7 males) aging $12.7 \pm 0.5$ years (8-16 years), with a height of $148 \pm 2.4 \mathrm{~cm}(127-167 \mathrm{~cm})$, weighing $33.9 \pm 1.8 \mathrm{~kg}(19.6-49$ $\mathrm{kg}$ ), and having a body mass index of $15.2 \pm 0.5 \mathrm{~kg} / \mathrm{m}^{2}\left(11.3-19.7 \mathrm{~kg} / \mathrm{m}^{2}\right)$.

From the 24 children enrolled into the study, spontaneous FOT could not be obtained in one child because of lack of cooperation and for half of them the 21-day assessment could not be performed because of loss of follow-up. For one child, we were unable to collect intraoperative data because of technical failure, and the second set of intraoperative forced oscillatory data was incomplete in three patients due to OR turnover. Finally, pulmonary hemodynamics was missed in 7 children for surgical reasons. Despite these missing values, we decided to include all consecutively enrolled patients in order to avoid sampling bias.

Table 1 summarizes the demographic parameters and clinical features of the children enrolled in the study. All children had clinical symptoms and were classified as New York Heart Association (NYHA) grade II and III. The most frequent etiology of their mitral valve disease was related to acute rheumatic fever. Postoperative transthoracic echocardiography revealed 
adequate outcome of the surgical repair with no-to-mild residual leak in all patients except 2 (F and $\mathrm{P}$ ) who required a redo for mitral valve replacement.

Perioperative changes in the airway and respiratory tissue mechanical parameters obtained during spontaneous breathing and during mechanical ventilation are demonstrated on Fig. 2. Parameters related to the flow resistance of the airways exhibited significant decreases both under spontaneous breathing $(\mathrm{p}<0.001)$ and in the operating theatre immediately after surgical repair of mitral diseases $(\mathrm{p}<0.005)$. The improvement in the airway properties was still detectable at 21 days postoperatively $(\mathrm{p}=0.002)$. The postoperative changes in the tissue elasticity were less consistent with $\mathrm{H}_{\mathrm{or}}$ increasing significantly immediately after the surgery $(\mathrm{p}=0.02)$, and an evidence for an improvement in $\operatorname{Ers}_{\mathrm{sp}} 5$ days postoperatively $(\mathrm{p}<0.005)$. The postoperative changes in $\mathrm{G}_{\mathrm{OR}}$ immediately after the surgery did not reach statistical significance $(\mathrm{p}=0.064)$.

Figure 3 demonstrates pulmonary arterial pressures before and immediately after the surgical correction of mitral valve diseases. Significant decreases in $\mathrm{Ppa}_{\mathrm{dia}}$ were observed postoperatively $(\mathrm{p}<0.02)$, whereas no statistically significant changes were detectable in $\mathrm{Ppa}_{\text {sys }}$ or $\mathrm{Ppa}_{\text {mean }}(\mathrm{p}=0.95$ and 0.35 , respectively).

Resistance and elastance expressed as percentage of reference values obtained in the children in the perioperative period during spontaneous breathing are depicted on Fig. 4. Before the surgical correction of the mitral valve disease, the values of both $\operatorname{Raw}_{\mathrm{sp}}$ and $\operatorname{Ers}_{\mathrm{sp}}$ were significantly higher than those expected in age-matched healthy controls ( $p<0.001$ for both). Furthermore, both mechanical parameters decreased significantly 5 days postoperatively $\left(\mathrm{p}<0.001\right.$ and $\mathrm{p}=0.014$ for $\mathrm{Raw}_{\mathrm{sp}}$ and $\mathrm{Ers}_{\mathrm{sp}}$, respectively), approaching the reference values 
obtained in healthy children. While at 21 days, there was still evidence for a statistical significant decrease in $\operatorname{Raw}_{\mathrm{sp}}(\mathrm{p}<0.005)$, the postoperative values of $\mathrm{Ers}_{\mathrm{sp}}$ at this time point did not differ significantly from the preoperative or normal values.

The associations between the magnitude of the airway and respiratory tissue parameters and the amount of their postoperative change are summarized on Fig. 5. The changes in both resistive and elastic parameters obtained during spontaneous breathing 5 days after the surgery exhibited close correlation with their preoperative initial levels. Postoperative changes in the mechanical parameters measured in the anesthetized children showed no close correlations with their preoperative initial values.

Since $\mathrm{Ppa}_{\mathrm{dia}}$ showed clear improvements after the surgery, the preoperative respiratory mechanical abnormalities were related to this pulmonary hemodynamic variable. Figure 6 panels A-B summarize these relationships by depicting the preoperative $\operatorname{Rrs}_{\mathrm{sp}}$ and $\operatorname{Ers}_{\mathrm{sp}}$ values expressed as percentage of reference values against the corresponding preoperative levels of $\mathrm{Ppa}_{\mathrm{dia}}$. No clear tendency was obvious between $\mathrm{Ppa}_{\mathrm{dia}}$ and $\mathrm{Raw}_{\mathrm{sp}}(\mathrm{Panel} \mathrm{A})$, whereas Ppa $\mathrm{dia}$ exhibited significant correlations with $\operatorname{Ers}_{\mathrm{sp}}$ (panel B). No clear associations were observed between the perioperative changes in $\mathrm{Ppa}_{\mathrm{dia}}$ and those in $\operatorname{Raw}_{\mathrm{sp}}\left(\right.$ panel C), $\operatorname{Ers}_{\mathrm{sp}}$ (panel D) and $\operatorname{Raw}_{\mathrm{OR}}$ (panel E). The changes in the airway properties measured during spontaneous breathing and during mechanical ventilation exhibited no close association either (Panel F).

\section{DiSCUSSION}

In the present study, we attempted to assess changes in the mechanical properties of the airways and the respiratory tissues following surgical repair of mitral valve disease. We demonstrated that airway properties improved significantly and immediately after surgery and 
remained in the normal range 21 days postoperatively. This improvement was correlated to the preoperative airway tone, but no correlation could be evidenced with the pulmonary hemodynamics. Conversely, respiratory tissue stiffness, which was correlated preoperatively to the diastolic pulmonary pressure, demonstrated an improvement only 5 days postoperatively. Moreover, this beneficial change correlated significantly with the preoperative respiratory elastance. However, there was no evidence for a clear immediate effect of surgery on the tissue mechanical parameters measured intraoperatively despite a decrease in diastolic pulmonary pressure.

Previous studies addressed the pulmonary consequences of surgical correction of mitral valve diseases via evaluating the lung functional changes by using spirometry or by estimating lung diffusion capacity ${ }^{21-24}$. To our knowledge, this is the first investigation that provides specific information about the perioperative trends in the airway and respiratory tissue mechanics. Well validated techniques were applied before, immediately after and in the follow-up period to measure airway and respiratory tissue mechanics in children under spontaneous breathing 18 and during mechanical ventilation ${ }^{14,19,25}$. While the two methods have common features, they differ in many aspects in estimating the respiratory mechanics. While $\mathrm{Zrs}_{\mathrm{OR}}$ excludes the upper airways and the trachea and is measured in supine position under general anesthesia with muscle relaxation, $\mathrm{Zrs}_{\mathrm{sp}}$ is measured in sitting position with the involvement of the upper airway mechanics. Thus, direct comparison of the airway and tissue mechanical parameters would not be straightforward, but their within-subject changes reflect alterations in these compartments accurately. Taking into account the age-dependence of the respiratory mechanical parameters, the values obtained in this study in children with post-capillary pulmonary hypertension are in line with those obtained previously in children with pulmonary hypertension resulting from left to right shunt (VSD) ${ }^{14,25}$. 
One of the main finding of the present study is the instantaneous improvement in the airway

It is noteworthy, that these children had abnormally high airway resistance prior to the surgery (Fig. 4), which returned to the normal range after weaning from postoperative cardiorespiratory support. Furthermore, this improvement was proportional to the severity of preoperative airway obstruction (Fig. 5) suggesting that this postoperative improvement has greater importance in the children with marked preoperative bronchoconstriction. In agreement with previous results ${ }^{29,} 30$, no clear association between the pulmonary hemodynamic improvement and the amount of airway dilation could be evidenced (Fig. 6). Thus, it is unlikely that a direct cardiopulmonary interdependence is responsible for this finding. The improvement in airway patency is rather due to the postoperative elevation in functional residual capacity ${ }^{31,32}$, which than provides greater mechanical support to the airways walls, thereby increasing their lumen.

In contrast with the consistent changes in the airway properties, tissue mechanical parameters exhibited dissociated changes postoperatively when they were assessed under mechanical 
ventilation immediately after $\mathrm{CPB}$, or days after the correction surgery (Fig. 2). While the beneficial changes were not reflected in the tissue mechanical parameters obtained in the immediate postoperative period. This apparent inconsistency can be explained by the inflammatory consequence of $\mathrm{CPB}$, which leads to interstitial water extravasation with consequent increase in respiratory tissue stiffness ${ }^{14,26,33-35}$. This phenomenon may mask the beneficial effect of decreased vascular engorgement on the viscoelastic properties of the respiratory system. The lack of change in $\mathrm{G}_{\mathrm{OR}}$ despite the improvement in Raw $\mathrm{OR}_{\mathrm{OR}}$ can also be attributed to the opposing effects of diminished postcapillary overload and the detrimental effects of CPB. Consequently, the decreased Raw ${ }_{O R}$ associated with increased $\mathrm{H}_{\mathrm{OR}}$ demonstrate the postoperative development of ventilation heterogeneities following $\mathrm{CPB}$, which is independent of the valve repair per $s e^{14}$.

Five days after the surgery, when all these confounding effects of CPB faded, the Ers $s_{\mathrm{sp}}$ improved significantly, particularly in the children with highly elevated preoperative respiratory tissue stiffness (Fig. 5). The close correlation between the preoperative level of $\operatorname{Ers}_{\mathrm{sp}}$ and Ppa $\mathrm{P}_{\mathrm{dia}}$ and the consistency between their beneficial postoperative changes (Fig. 6) suggest the presence of a close association between pulmonary hemodynamics and tissue mechanics in children with mitral disease. This finding is in line with earlier results demonstrating the presence of increased tissue stiffness in children with mitral valve disease and its reversal following the correction surgery ${ }^{31,32}$. However, we cannot exclude the additive effect of postoperative diuretics and negative fluid balance in these children in the improvement of tissue elastance obtained 5 days after the surgery. The tendency for a stiffening of the respiratory tissues 21 days postoperatively despite the success of mitral valve surgery (Figs 2 and 4) suggests the presence of irreversible pulmonary interstitial changes, at 
least in the follow-up time frame. This rebound is consistent with earlier results demonstrating that despite the temporal decongestion of the pulmonary interstitium, a sustained remodeling of the alveolar wall structure remains in the presence of a chronic heart disease with postcapillary pulmonary overload ${ }^{21}$.

In summary, perioperative assessment of airway and respiratory tissue mechanics revealed that children with mitral valve disease exhibit abnormal airway and respiratory tissue mechanics when these lung function parameters are related to age-matched healthy controls. The adverse alteration in the respiratory elastance was directly related to the pulmonary heamodynamical impairment, whereas the diminished airway properties showed no clear associations with the severity of the pulmonary hypertension. Both airway and tissue mechanical parameters exerted beneficial short-term improvements 5 days postoperatively. Nevertheless, sustained enlargement of the airway caliber remained 21 days postoperatively while persistence of tissue stiffness was still detected in the late follow-up. These findings indicate that clinical symptoms related to airway narrowing (wheezing, cough) are expected to be alleviated postoperatively, whereas impairment in lung function may persist even after weeks due to residual lung tissue stiffening. 


\section{REFERENCES}

1. McDonald M, Currie BJ, Carapetis JR: Acute rheumatic fever: a chink in the chain that links the heart to the throat? The Lancet infectious diseases. 4:240-245, 2004.

2. Seckeler MD, Hoke TR: The worldwide epidemiology of acute rheumatic fever and rheumatic heart disease. Clinical epidemiology. 3:67-84, 2011.

3. Gehlbach BK, Geppert E: The pulmonary manifestations of left heart failure. Chest. 125:669-682, 2004.

4. Snashall PD, Chung KF: Airway obstruction and bronchial hyperresponsiveness in left ventricular failure and mitral stenosis. Am Rev Respir Dis. 144:945-956, 1991.

5. Lockhart A, Dinh-Xuan AT, Regnard J, et al.: Effect of airway blood flow on airflow. Am Rev Respir Dis. 146:S19-23, 1992.

6. Cabanes LR, Weber SN, Matran R, et al.: Bronchial hyperresponsiveness to methacholine in patients with impaired left ventricular function. $\mathrm{N}$ Engl $\mathrm{J}$ Med. 320:1317-1322, 1989.

7. Pison C, Malo JL, Rouleau JL, et al.: Bronchial hyperresponsiveness to inhaled methacholine in subjects with chronic left heart failure at a time of exacerbation and after increasing diuretic therapy. Chest. 96:230-235, 1989.

8. Wiggs BR, Bosken C, Pare PD, et al.: A model of airway narrowing in asthma and in chronic obstructive pulmonary disease. Am Rev Respir Dis. 145:1251-1258, 1992.

9. Rolla G, Bucca C, Caria E, et al.: Bronchial responsiveness in patients with mitral valve disease. Eur Respir J. 3:127-131, 1990.

10. Nishimura $\mathrm{Y}$, Maeda H, Yokoyama M, et al.: Bronchial hyperreactivity in patients with mitral valve disease. Chest. 98:1085-1090, 1990.

11. Ishii M, Matsumoto N, Fuyuki T, et al.: Effects of hemodynamic edema formation on peripheral vs. central airway mechanics. J Appl Physiol. 59:1578-1584, 1985.

12. Albu G, Petak F, Fontao F, et al.: Mechanisms of airway hyper-responsiveness after coronary ischemia. Respiratory physiology \& neurobiology. 162:176-183, 2008.

13. Uhlig $\mathrm{T}$, Wildhaber $\mathrm{JH}$, Carroll $\mathrm{N}$, et al.: Pulmonary vascular congestion selectively potentiates airway responsiveness in piglets. Am J Respir Crit Care Med. 161:13061313, 2000.

14. von Ungern-Sternberg BS, Petak F, Hantos Z, et al.: Changes in functional residual capacity and lung mechanics during surgical repair of congenital heart diseases: 
effects of preoperative pulmonary hemodynamics. Anesthesiology. 110:1348-1355, 2009.

15. Petak F, Albu G, Lele E, et al.: Prevention of airway hyperresponsiveness induced by left ventricular dysfunction in rats. Respir Res. 13:114, 2012.

16. Oostveen E, MacLeod D, Lorino H, et al.: ERS Task Force on Respiratory Impedance Measurements. The forced oscillation technique in clinical practice: methodology, recommendations and future developments. Eur Respir J. 22:1026-1041, 2003.

17. Petak F, Hantos Z, Adamicza A, et al.: Methacholine-induced bronchoconstriction in rats: effects of intravenous vs. aerosol delivery. J Appl Physiol. 82:1479-1487, 1997.

18. Hantos Z, Daroczy B, Gyurkovits K: Total respiratory impedance in healthy children. Pediatr Pulmonol. 1:91-98, 1985.

19. Petak F, Babik B, Asztalos T, et al.: Airway and tissue mechanics in anesthetized paralyzed children. Pediatr Pulmonol. 35:169-176, 2003.

20. Hantos Z, Daroczy B, Suki B, et al.: Input impedance and peripheral inhomogeneity of dog lungs. J Appl Physiol. 72:168-178, 1992.

21. Gomez-Hospital JA, Cequier A, Romero PV, et al.: Persistence of lung function abnormalities despite sustained success of percutaneous mitral valvotomy: the need for an early indication. Chest. 127:40-46, 2005.

22. Ota $\mathrm{T}$, Tsukube $\mathrm{T}$, Matsuda $\mathrm{H}$, et al.: Effect of mitral valve surgery on severely impaired pulmonary function. The Thoracic and cardiovascular surgeon. 42:94-99; discussion 99-102, 1994.

23. Ohno K, Nakahara K, Hirose H, et al.: Effects of valvular surgery on overall and regional lung function in patients with mitral stenosis. Chest. 92:224-228, 1987.

24. Mustafa KY, Nour MM, Shuhaiber $\mathrm{H}$, et al.: Pulmonary function before and sequentially after valve replacement surgery with correlation to preoperative hemodynamic data. Am Rev Respir Dis. 130:400-406, 1984.

25. Habre W, Schutz N, Pellegrini M, et al.: Preoperative pulmonary hemodynamics determines changes in airway and tissue mechanics following surgical repair of congenital heart diseases. Pediatr Pulmonol. 38:470-476, 2004.

26. Babik B, Asztalos T, Petak F, et al.: Changes in respiratory mechanics during cardiac surgery. Anesth Analg. 96:1280-1287, table of contents, 2003.

27. Fan Chung K: Phosphodiesterase inhibitors in airways disease. Eur J Pharmacol. 533:110-117, 2006. 
28. Waldeck B: Beta-adrenoceptor agonists and asthma--100 years of development. Eur J Pharmacol. 445:1-12, 2002.

29. Hryniewiecki T, Rawczynska-Englert I, Malinowski R, et al.: [Analysis of airway function in patients with mitral valve disease in various stages of progression]. Przeglad lekarski. 56:270-275, 1999.

30. Lanteri CJ, Kano S, Duncan AW, et al.: Changes in respiratory mechanics in children undergoing cardiopulmonary bypass. Am J Respir Crit Care Med. 152:1893-1900, 1995.

31. Palmer WH, Gee JB, Bates DV: Disturbances of Pulmonary Function in Mitral Valve Disease. Canadian Medical Association journal. 89:744-750, 1963.

32. Morris MJ, Smith MM, Clarke BG: Lung mechanics after cardiac valve replacement. Thorax. 35:453-460, 1980.

33. Tonz M, Mihaljevic $\mathrm{T}$, von Segesser LK, et al.: Acute lung injury during cardiopulmonary bypass. Are the neutrophils responsible? Chest. 108:1551-1556, 1995.

34. Vincent RN, Lang P, Elixson EM, et al.: Extravascular lung water in children immediately after operative closure of either isolated atrial septal defect or ventricular septal defect. The American journal of cardiology. 56:536-539, 1985.

35. Gilliland HE, Armstrong MA, McMurray TJ: The inflammatory response to pediatric cardiac surgery: correlation of granulocyte adhesion molecule expression with postoperative oxygenation. Anesthesia and analgesia. 89:1188-1191, 1999. 
Table 1 - Physical and Clinical Data of Patients

\begin{tabular}{|c|c|c|c|c|c|c|}
\hline Children & $\begin{array}{l}\text { Age } \\
\text { (year) }\end{array}$ & $\begin{array}{l}\text { Height } \\
(\mathrm{cm})\end{array}$ & $\begin{array}{l}\text { Weight } \\
(\mathrm{kg})\end{array}$ & $\begin{array}{c}\text { Preoperative } \\
\text { Treatment }\end{array}$ & $\begin{array}{c}\text { Diagnosis } \\
\text { (Preoperative ultrasound) }\end{array}$ & $\begin{array}{c}\text { Inotrope after } \\
\text { bypass }\end{array}$ \\
\hline
\end{tabular}

\begin{tabular}{|c|c|c|c|c|c|c|c|}
\hline A & 14 & 153.5 & 30 & $\mathrm{~F}, \mathrm{~S}$ & Severe MI, Moderate AI & $\mathrm{M}, \mathrm{A}$ & F, S, E \\
\hline B & 14 & 153.5 & 29.6 & $\mathrm{~F}, \mathrm{~S}$ & $\begin{array}{c}\text { Severe MI, Moderate AI } \\
\text { Mild TI }\end{array}$ & M, Do & F, S, E \\
\hline $\mathrm{C}$ & 16 & 152 & 44 & none & $\begin{array}{c}\text { ASD, VSD* } \\
\text { Severe MI, Mild TI }\end{array}$ & Do & $\mathrm{F}, \mathrm{E}$ \\
\hline $\mathrm{D}$ & 15 & 167 & 49 & $\mathrm{~F}, \mathrm{~S}$ & $\begin{array}{l}\text { Severe MS and MI } \\
\text { Moderate AI }\end{array}$ & none & F, S, E \\
\hline $\mathrm{E}$ & 13 & 162 & 33 & $\mathrm{~F}$ & Severe MS, Mild MI & Do & F, S, E \\
\hline $\mathrm{F}$ & 14 & 147 & 32 & $\mathrm{~F}, \mathrm{~S}, \mathrm{E}$ & Severe MI & $\mathrm{M}, \mathrm{P}$ & $\mathrm{F}, \mathrm{S}$ \\
\hline $\mathrm{G}$ & 8 & 142.5 & 28.3 & $\mathrm{~F}, \mathrm{E}$ & Severe MI, Mild TI* & Do & F, S, E \\
\hline $\mathrm{H}$ & 8 & 130 & 22.8 & $\mathrm{~F}$ & Severe MI* & $\mathrm{A}, \mathrm{Ne}$ & F, S, E \\
\hline $\mathrm{I}$ & 12 & 148 & 30 & $\mathrm{~F}, \mathrm{E}$ & Severe MI* & Do & F, S, E \\
\hline $\mathrm{J}$ & 15 & 153 & 39.5 & $\mathrm{~F}, \mathrm{~S}, \mathrm{E}$ & $\begin{array}{c}\text { Severe MI, Moderate TI } \\
\text { Mild AI }\end{array}$ & $\mathrm{M}, \mathrm{A}, \mathrm{P}$ & F, S, E \\
\hline K & 14 & 133 & 24.3 & $\mathrm{~F}, \mathrm{~S}$ & Severe MI, Mild TI & Do & $\mathrm{F}$ \\
\hline $\mathrm{L}$ & 14 & 158 & 42 & $\mathrm{~F}, \mathrm{~S}$ & Severe MI & Do & F, S, E \\
\hline M & 12 & 148 & 30 & $\mathrm{~F}, \mathrm{~S}, \mathrm{E}$ & Severe MI & M & F, S, E \\
\hline $\mathrm{N}$ & 13 & 131 & 24.4 & $\mathrm{~F}, \mathrm{~S}, \mathrm{E}$ & Severe MI, Moderate AI & Not documented & \\
\hline $\mathrm{O}$ & 12 & 153 & 46 & $\mathrm{~F}, \mathrm{~S}$ & Severe MI, Severe IA & Am, M & F, S, E \\
\hline $\mathrm{P}$ & 10 & 143 & 43 & $\mathrm{~F}, \mathrm{~S}$ & Severe MI & $\mathrm{A}, \mathrm{M}$ & F, S, E \\
\hline Q & 11 & 136 & 27.6 & none & Severe MI & Do & F, S, E \\
\hline $\mathrm{R}$ & 15 & 163 & 39.9 & $\mathrm{E}$ & Severe MI, Mild AI & Do & F, S, E \\
\hline $\mathrm{S}$ & 13 & 160 & 36.7 & $\mathrm{~S}, \mathrm{~T}$ & $\begin{array}{l}\text { Severe MS and MI, } \\
\text { moderate TI }\end{array}$ & M, Do & F, S, E \\
\hline $\mathrm{T}$ & 11 & 132.5 & 31 & none & Severe MI* & M & $\mathrm{F}, \mathrm{S}$ \\
\hline $\mathrm{U}$ & 13 & 127 & 19.6 & $\mathrm{~F}, \mathrm{~S}, \mathrm{E}$ & Severe MI, Severe TI* & Do & \\
\hline $\mathrm{V}$ & 15 & 159 & 32 & $\mathrm{~F}, \mathrm{~S}, \mathrm{E}$ & Severe MI, Moderate TI & none & F, S, E \\
\hline W & 15 & 163 & 49 & $\mathrm{~T}, \mathrm{~S}, \mathrm{E}$ & Moderate MI Severe AI, & Not documented & F, S, E \\
\hline $\mathrm{X}^{1}$ & 13 & 145 & 30 & $\mathrm{~F}, \mathrm{D}$ & Severe MI, Severe TI & none & $\mathrm{F}, \mathrm{E}$ \\
\hline
\end{tabular}


MI = Mitral insufficiency; $\mathrm{MS}=$ mitral stenosis; $\mathrm{AI}=$ aortic insufficiency; $\mathrm{TI}=$ tricuspid insufficiency; VSD = ventricular septal defect; ASD = atrial septal defect. $*=$ congenital etiology of mitral valve disease.

Pre- and postoperative treatment: F: furosemide, S: spironalactone, E: enalapril, D: digoxin, T: thiazide.

Inotrope after weaning from bypass: $\mathrm{Do}=$ Dobutamine, $\mathrm{M}=$ Milrinone, $\mathrm{A}=$ Adrenaline, $\mathrm{Am}=$ amiodarone, $\mathrm{Ne}=$ norepinephrine; $\mathrm{P}=$ Phenylephrine .

1 = latent tuberculosis 


\section{FIGURE CAPTIONS}

Figure 1: Scheme of the experimental protocol. $\mathrm{Zrs}_{\mathrm{sp}}$ : forced oscillatory input impedance measurement during spontaneous breathing. Zrs ${ }_{\mathrm{OR}}$ : forced oscillatory input impedance measurement during mechanical ventilation under general anesthesia. Ppa: assessment of pulmonary arterial pressure.

Figure 2: Airway and respiratory tissue mechanical parameters obtained in spontaneously breathing children ( $\operatorname{Raw}_{\mathrm{sp}}$ : airway resistance, Erssp: respiratory system elastance) and during mechanical ventilation (Raw ${ }_{\mathrm{OR}}$ : airway resistance, $\mathrm{G}_{\mathrm{OR}}$ : tissue damping, $\mathrm{H}_{\mathrm{OR}}$ : tissue elastance) on the day before the surgery (D0), immediately before and after the mitral valve surgery in the operating room (Bef, Aft) and 5 (D5) and 21 (D21) days postoperatively. *: significant change vs. the corresponding value at D0 or Bef. Thin lines with various symbols: data points in the individual patients, thick line: group means, box plots: median and 10\%, 25\%, $75 \%$, and $90 \%$ percentiles.

Figure 3: Pulmonary arterial pressure parameters immediately before (Bef) and after (Aft) the mitral valve surgery in the operating room (Bef, Aft). Thin lines with various symbols: data points in the individual patients, thick line: group means, box plots: median and 10\%, 25\%, 75\%, and 90\% percentiles. *: $\mathrm{p}<0.05$ vs. Bef.

Figure 4: Airway resistance $\left(\operatorname{Raw}_{\mathrm{sp}}\right)$ and elastance $\left(\operatorname{Ers}_{\mathrm{sp}}\right)$ expressed as percentage of healthy age matched controls obtained by forced oscillations during spontaneous breathing on the day before the surgery (D0), and 5 (D5) and 21 (D21) days postoperatively. Thin lines with various symbols: data points in the individual patients, thick line: group means, box plots: median and 10\%, 25\%, $75 \%$, and $90 \%$ percentiles. *: $\mathrm{p}<0.05$ vs. D0.

Figure 5: Relationships between the magnitude of the airway resistance and elastance obtained during spontaneous breathing $\left(\operatorname{Raw}_{\mathrm{sp}}, \mathrm{Ers}_{\mathrm{sp}}\right)$ and during mechanical ventilation $\left(\operatorname{Raw}_{\mathrm{OR}}\right.$, $\left.\mathrm{Ers}_{\mathrm{OR}}\right)$ and their postoperative percentage change. Lines: best fit hyperbolas.

Figure 6: Panels A-B: relationships between diastolic pulmonary arterial pressure $\left(\mathrm{Ppa}_{\mathrm{dia}}\right)$ and the airway resistance and elastance obtained during spontaneous breathing $\left(\operatorname{Raw}_{\mathrm{sp}}\right.$, $\operatorname{Ers}_{\mathrm{sp}}$, both expressed as \% of normal values). Panels C-E: relationships between pperioperative changes in the diastolic pulmonary arterial pressure $\left(\mathrm{Ppa}_{\mathrm{dia}}\right)$ and the airway resistance and elastance obtained during 
spontaneous breathing $\left(\mathrm{dRaw}_{\mathrm{sp}}, \mathrm{dErs}_{\mathrm{sp}}\right)$ and during mechanical ventilation $\left(\operatorname{Raw}_{\mathrm{OR}}\right)$. Panel $\mathrm{F}$ : relationship between airway resistance parameters obtained under spontaneous breathing $\left(\operatorname{Raw}_{\mathrm{sp}}\right)$ and during mechanical ventilation $\left(\mathrm{Raw}_{\mathrm{OR}}\right)$. Lines: linear regression. 


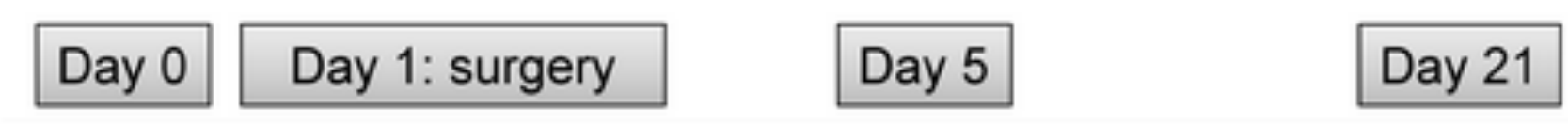
Time

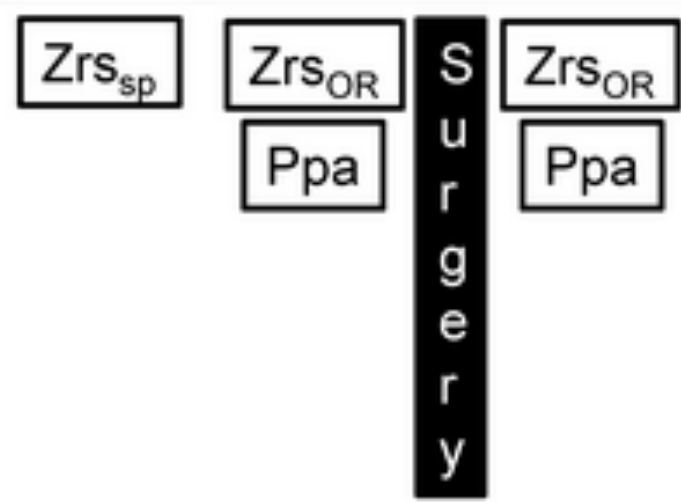



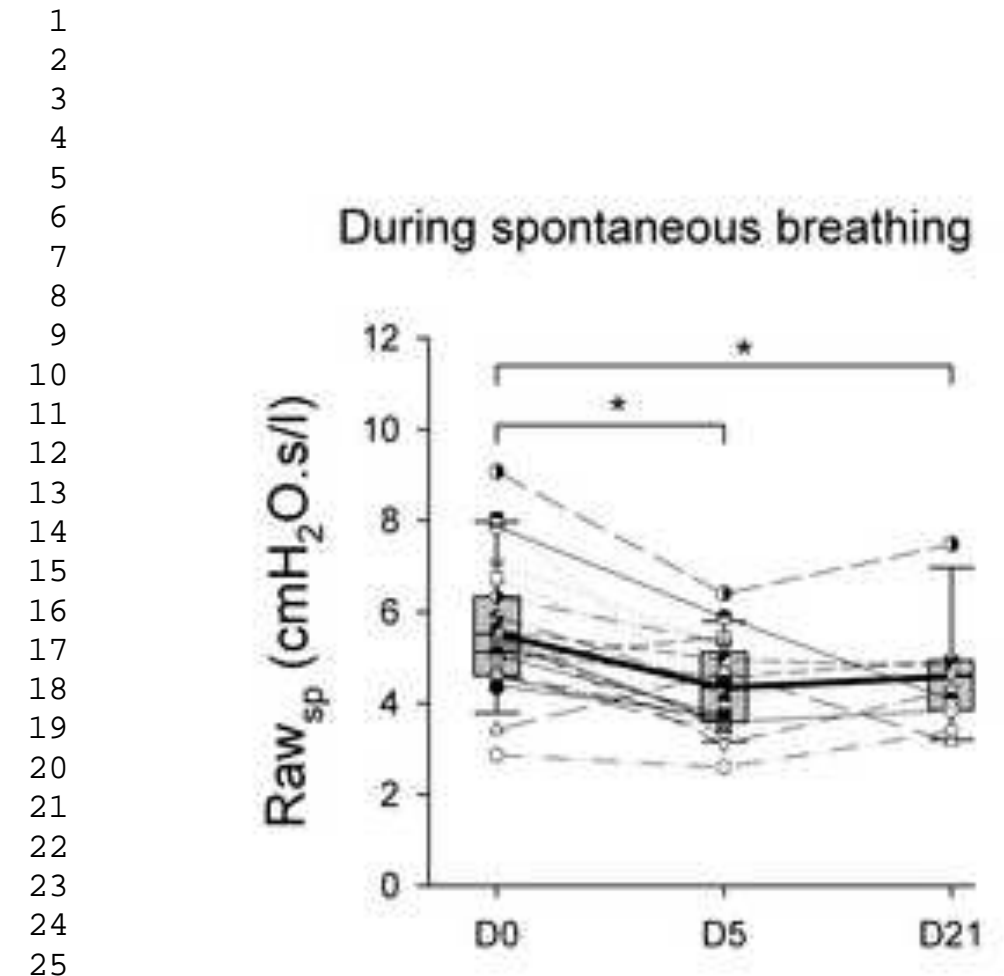

\section{During mechanical ventilation}
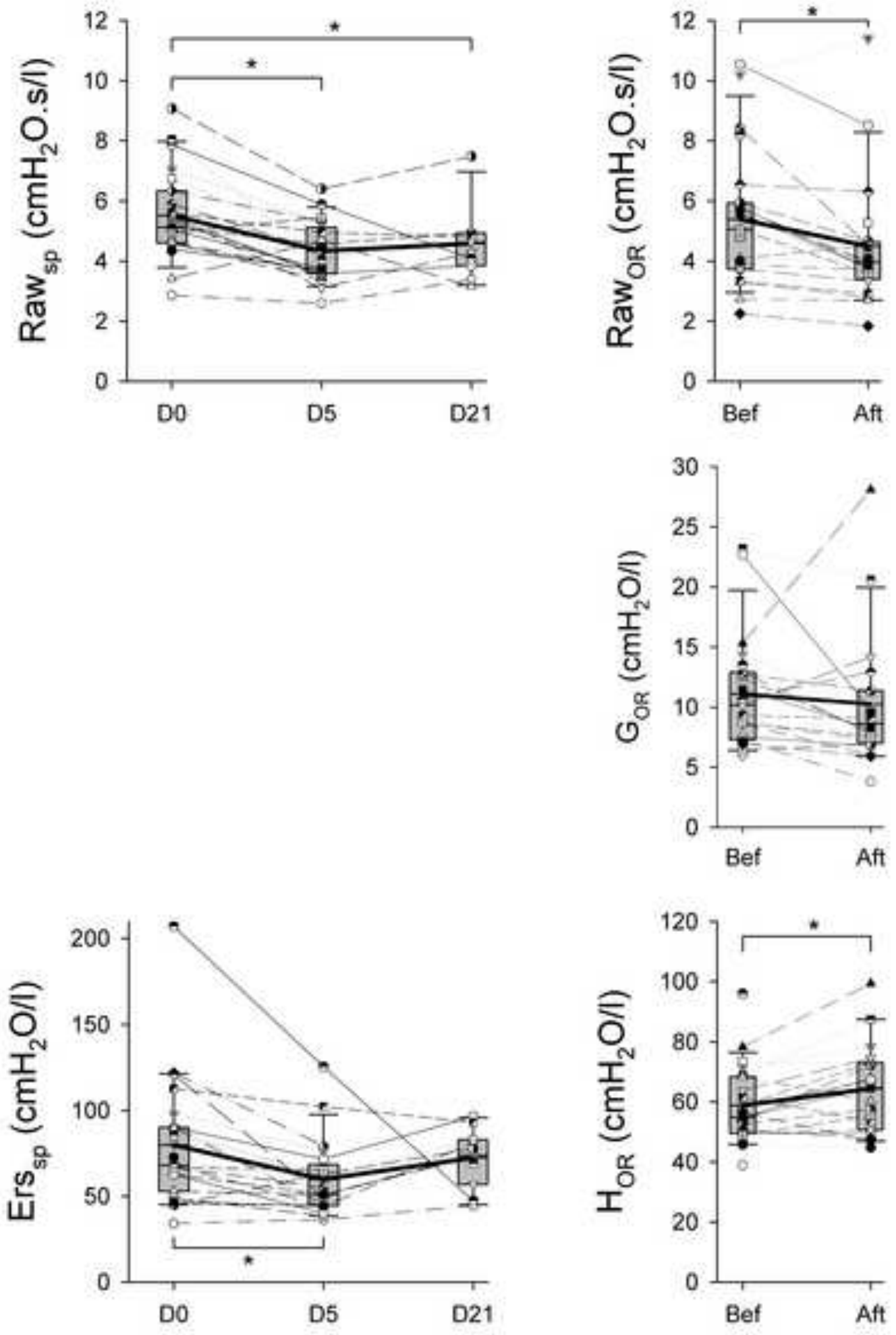

Figure 2 
Click here to download high resolution image
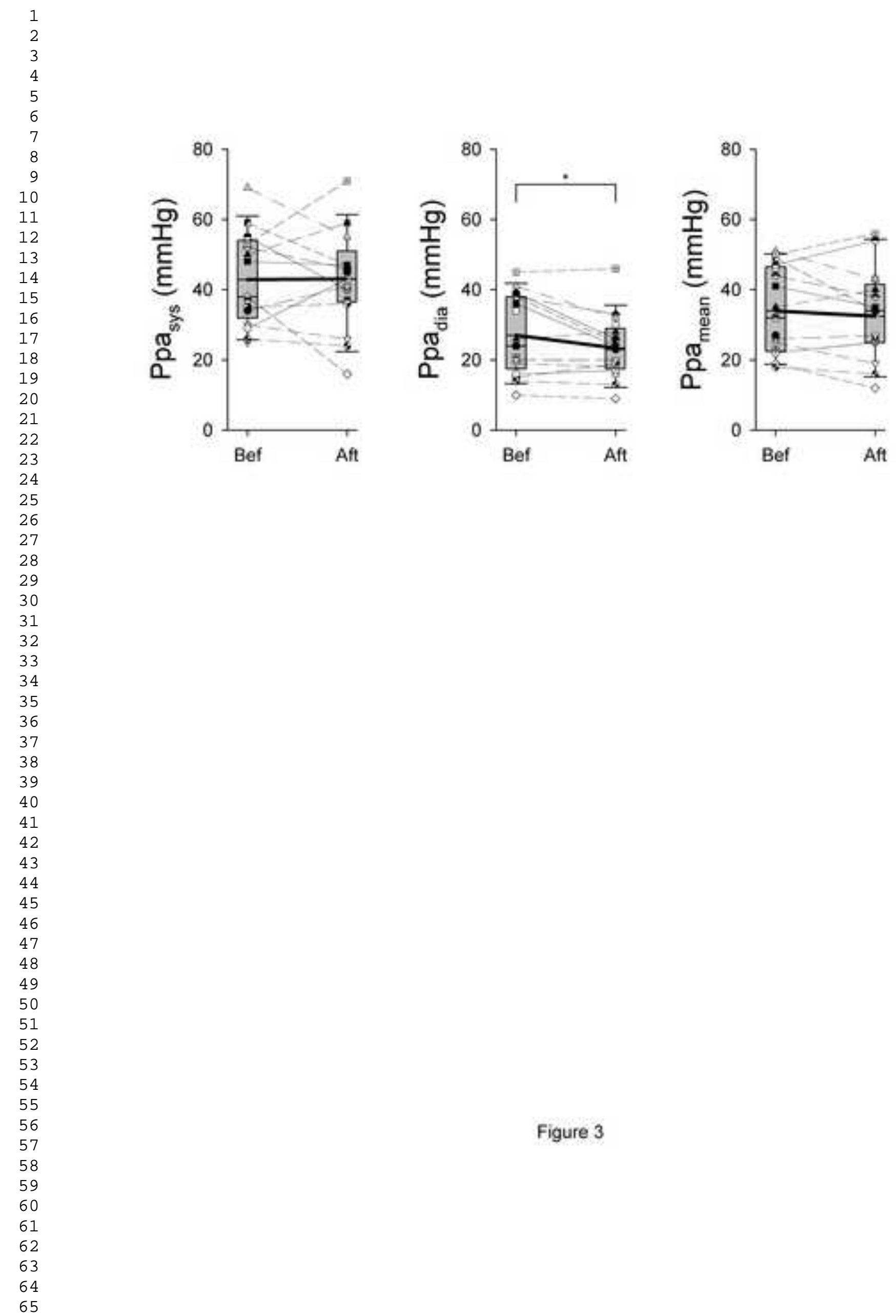

\section{Figure 3}


Click here to download high resolution image

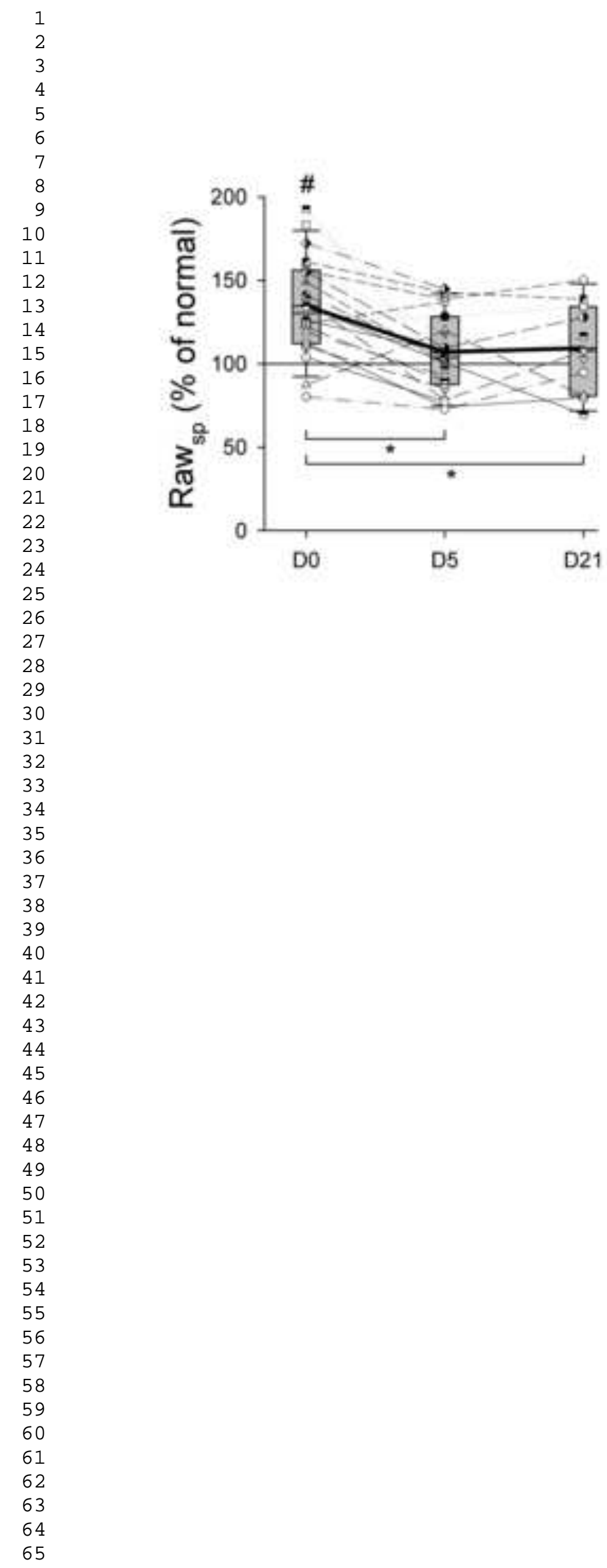

Figure 4

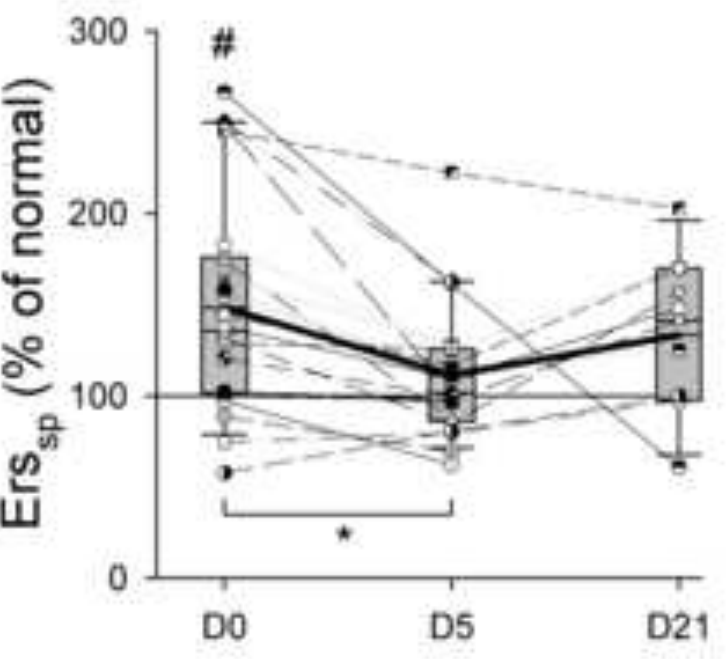

Fine 4 


\section{Figure}

Click here to download high resolution image
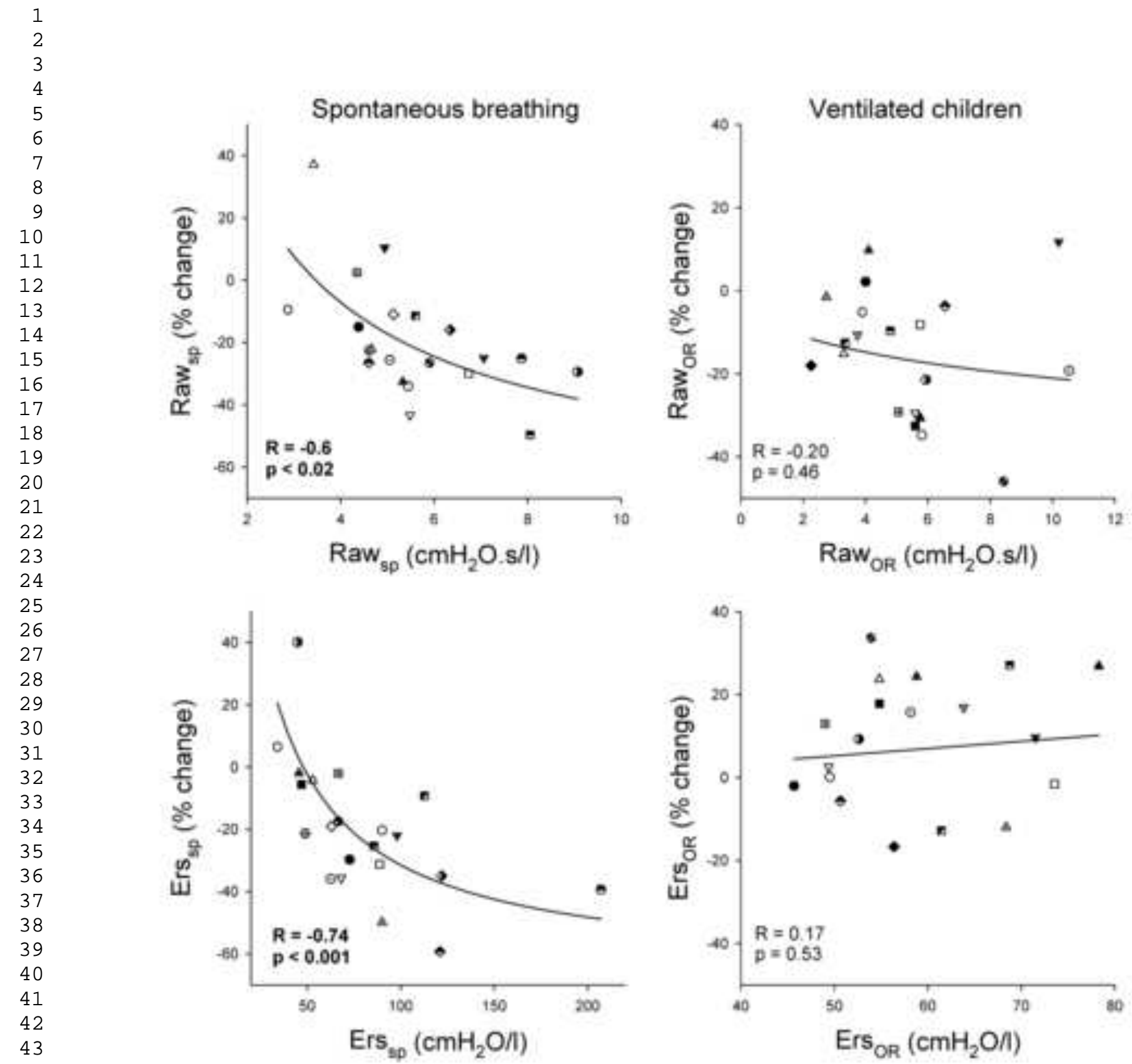

44

45

46

47

48

49

50

51

52

53

54

55

56

57

58 


\section{Figure}

Click here to download high resolution image
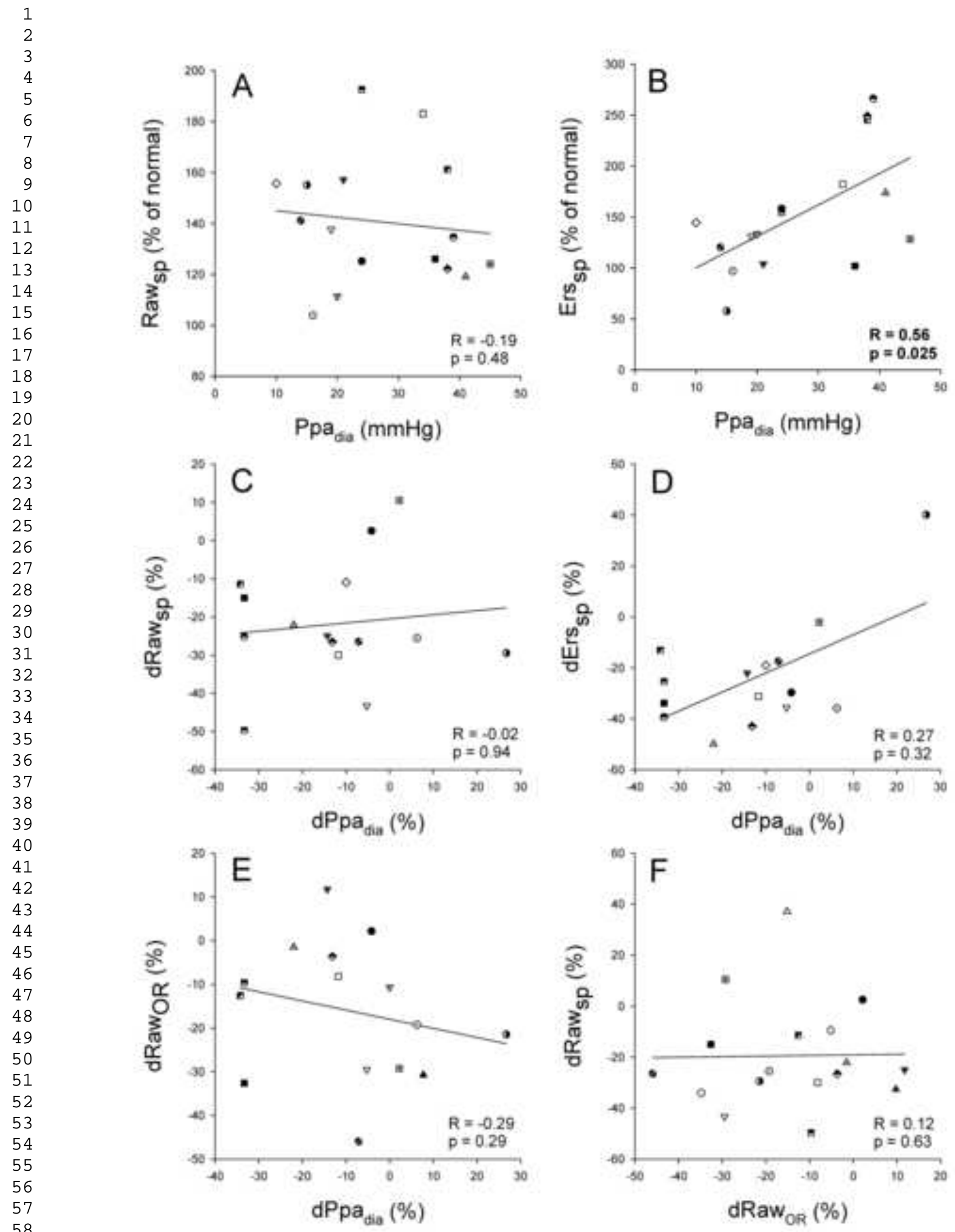

Figure 6 